\title{
The 3' Splice Site of Influenza A Segment 7 mRNA Can Exist in Two Conformations: A Pseudoknot and a Hairpin
}

\author{
Walter N. Moss ${ }^{19}$, Lumbini I. Dela-Moss ${ }^{19}$, Elzbieta Kierzek ${ }^{2}$, Ryszard Kierzek ${ }^{2}$, Salvatore F. Priore ${ }^{1}$, \\ Douglas H. Turner ${ }^{1 *}$
}

1 Department of Chemistry, Center for RNA Biology, University of Rochester, Rochester, New York, United States of America, 2 Institute of Bioorganic Chemistry, Polish Academy of Sciences, Poznan, Noskowskiego, Poland

\begin{abstract}
The $3^{\prime}$ splice site of influenza A segment 7 is used to produce mRNA for the M2 ion-channel protein, which is critical to the formation of viable influenza virions. Native gel analysis, enzymatic/chemical structure probing, and oligonucleotide binding studies of a $63 \mathrm{nt}$ fragment, containing the $3^{\prime}$ splice site, key residues of an SF2/ASF splicing factor binding site, and a polypyrimidine tract, provide evidence for an equilibrium between pseudoknot and hairpin structures. This equilibrium is sensitive to multivalent cations, and can be forced towards the pseudoknot by addition of $5 \mathrm{mM}$ cobalt hexammine. In the two conformations, the splice site and other functional elements exist in very different structural environments. In particular, the splice site is sequestered in the middle of a double helix in the pseudoknot conformation, while in the hairpin it resides in a two-by-two nucleotide internal loop. The results suggest that segment 7 mRNA splicing can be controlled by a conformational switch that exposes or hides the splice site.
\end{abstract}

Citation: Moss WN, Dela-Moss LI, Kierzek E, Kierzek R, Priore SF, et al. (2012) The 3' Splice Site of Influenza A Segment 7 mRNA Can Exist in Two Conformations: A Pseudoknot and a Hairpin. PLoS ONE 7(6): e38323. doi:10.1371/journal.pone.0038323

Editor: Alfred Lewin, University of Florida, United States of America

Received March 22, 2012; Accepted May 3, 2012; Published June 7, 2012

Copyright: (c) 2012 Moss et al. This is an open-access article distributed under the terms of the Creative Commons Attribution License, which permits unrestricted use, distribution, and reproduction in any medium, provided the original author and source are credited.

Funding: This work was supported by National Institutes of Health (NIH) R01 GM22939. The funders had no role in study design, data collection and analysis, decision to publish, or preparation of the manuscript.

Competing Interests: The authors have declared that no competing interests exist.

*E-mail: turner@chem.rochester.edu

9 These authors contributed equally to this work.

\section{Introduction}

Pandemic outbreaks of influenza A were responsible for millions of deaths in the $20^{\text {th }}$ century. Notably, the Spanish Flu of 1918 killed between 20 [1] and 100 million people [2]. Influenza is still of grave concern to public health. Each year globally there are an estimated three to five million severe infections with up to 500,000 deaths [3]; in the U.S. alone there are approximately 200,000 hospitalizations and 36,000 deaths yearly $[4,5,6]$. Most therapeutics target influenza proteins: e.g. blocking the M2 ion channel with amantadine and rimantadine [7]). The virus, however, utilizes RNA at every step in its propagation, making viral RNA an attractive target for therapeutic treatment [8,9]. A better understanding of the structure and function of RNA in influenza A would open new avenues for treatment of this deadly disease, and provide a valuable complement to current therapeutics.

The influenza A virus possesses an eight segment (-) sense RNA genome, which codes for at least eleven proteins. Fragments of the influenza A coding RNA are predicted to have unusual thermodynamic stability, and also have suppressed third codon position variability. In combination with conserved base pairing, these results provided predictions of fragments likely to fold into functional structures [10]. One particularly interesting fragment (Fig. 1) includes the $3^{\prime}$ splice site of segment 7, as well as key residues of a binding site for the human SF2/ASF splicing factor [11] and a polypyrimidine tract that may bind other splicing factors such as U2AF65 [12,13]. Segment 7 encodes the M1 matrix protein and three alternatively spliced products that share the $3^{\prime}$ splice site: the M2 protein, the small M3 polypeptide, and occasionally M4 [14]. Production of M2 is critical for uncoating of the viral genome and splicing of the M2 mRNA is temporally controlled [15].

Secondary structure modeling of the $3^{\prime}$ splice site of segment 7 (Fig. 1) yielded the possibility of two alternative conformations: (1) a pseudoknot (Fig. 1B), where the splice site is base paired in a helix and (2) a hairpin (Fig. 1C), where the splice site occurs in a two-bytwo nt internal loop [10]. Native gel analysis, enzymatic/chemical structure probing, and oligonucleotide binding studies reported here for a $63 \mathrm{nt}$ fragment are consistent with these models. A similar hairpin/pseudoknot was described for the 3 ' splice site of segment 8, which was proposed to influence splicing of the NS2 mRNA [16,17]. These results suggest that splicing of segment 7 may be modulated by varying splice site accessibility [18,19,20,21] or splicing factor binding [22,23,24], and that conformational switching may be a common mechanism to control splicing of influenza genes. Small molecules [25,26,27,28,29] or oligonucleotides $[30,31,32]$ that specifically bind to these structures could be used to test their function and potentially provide leads for therapeutics.

\section{Results}

Native Gel Electrophoresis Reveals Two Conformations

Native gels were run with a $63 \mathrm{nt}$ fragment of an avian influenza A 3' splice site (3PSS) from segment 7, alongside an artificial mutant construct (HPMut) that can fold into a hairpin but not 


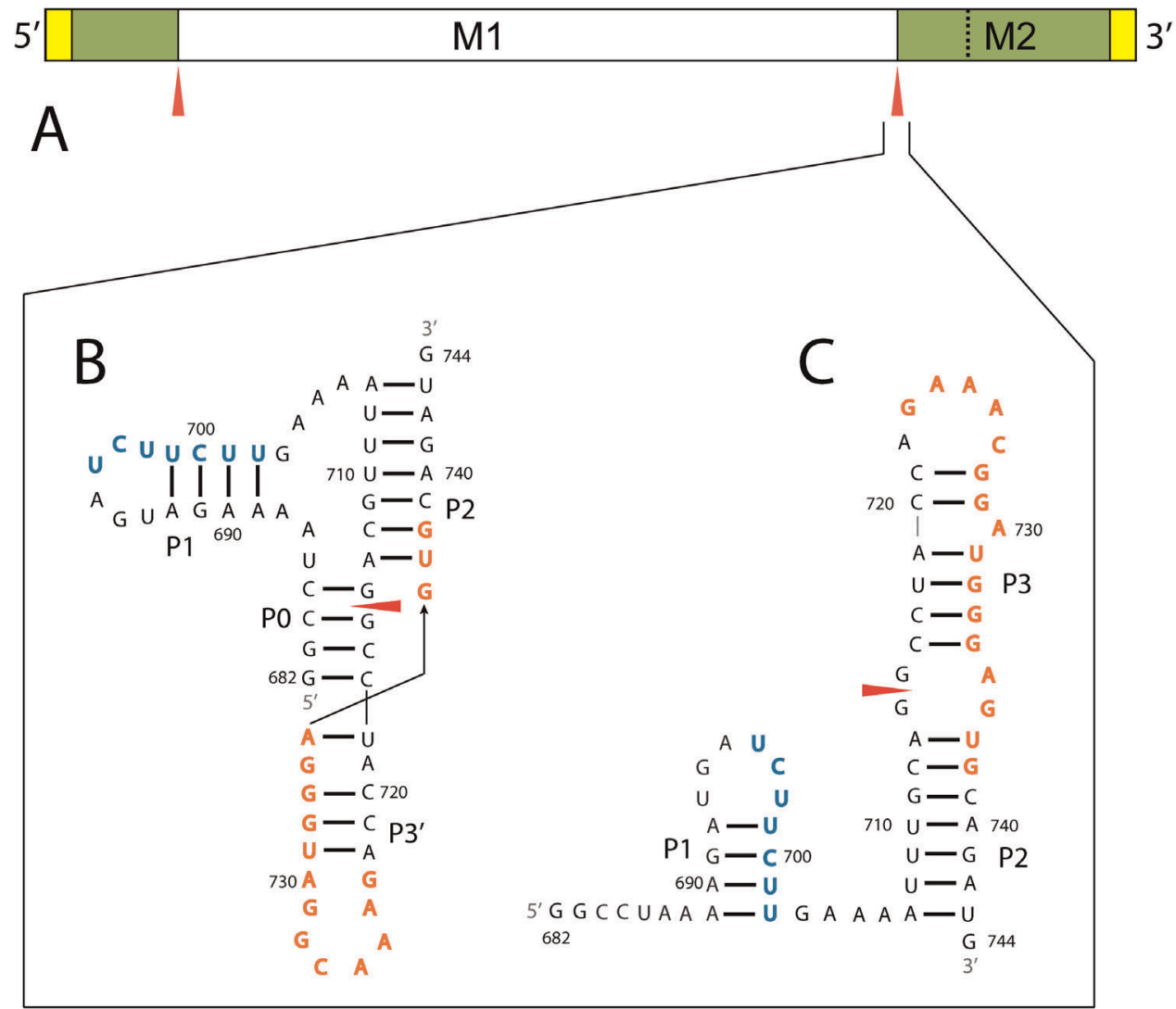

Figure 1. Location and structure of the $\mathbf{3}^{\prime}$ splice site. (A) Segment 7 mRNA annotated with the splice sites (red arrow), UTRs (yellow box), and $\mathrm{M} 1$ and $\mathrm{M} 2$ open reading frames. M1 and M2 share the same start site, but M1 stops within the M2 ORF (at the black dotted line). Splicing combines the two green boxes to form the M2 open reading frame. (B) Predicted pseudoknot (PK) model with 3' splice site annotation (red arrow), an SF2/ASF exonic splicing enhancer binding site in orange, and a polypyrimidine tract in blue. (C) Predicted hairpin (HP) model with same annotations as B. In order to isolate a single conformation, specific mutations were introduced to change nts 684 to 686 into A's and to swap GC for CG at pairs 716-734 and 717-733 to forbid the pseudoknot and only allow the hairpin fold (HPMut).

doi:10.1371/journal.pone.0038323.g001

a pseudoknot. Specifically, in HPMut, nucleotides 684-6 are changed to adenosines (Fig. 1B) and the two hairpin CG pairs at nucleotides 716-734 and 717-733 are swapped to make GC pairs (Fig. 1C); both changes forbid formation of the pseudoknot P0 helix while maintaining the hairpin. When the wild type sequence is folded in the presence of $\mathrm{Mg}^{2+}$, two bands are observed (Fig. 2A). The faster running of the two major bands observed for 3PSS (lanes 4-9 of Fig. 2A) migrates similar to HPMut (lane 1 of Fig. 2A). This suggests that the faster running band is the hairpin (HP) conformation of 3PSS and, by exclusion, that the slower running band is the pseudoknot (PK) conformation.

In the absence of multivalent cations there is no observable amount of PK (Fig. 2A lane 3; $2 \mathrm{~B}$ lane 1). In the presence of $\mathrm{Mg}^{2+}$, 3PSS folds into both HP and PK conformations (Fig. 2A) but even with $25 \mathrm{mM} \mathrm{Mg}^{2+} \mathrm{PK}$ never becomes dominant (Fig. 2A lane 9). However, when 3PSS is incubated with $5 \mathrm{mM}$ cobalt (III) hexammine $\left(\left[\mathrm{Co}\left(\mathrm{NH}_{3}\right)_{6}\right]^{3+}\right)$, the dominant product becomes PK (Fig. 2B, lane 7). Henceforth, 3PSS will be referred to as PK when in the presence of $5 \mathrm{mM}\left[\mathrm{Co}\left(\mathrm{NH}_{3}\right)_{6}\right]^{3+}$ and as $\mathrm{HP}$ when in the presence of only $100 \mathrm{mM} \mathrm{KCl}$.

\section{Enzymatic and Chemical Mapping of RNA Secondary Structure}

To study individual conformations, mapping was carried out on 3PSS with $100 \mathrm{mM} \mathrm{KCl}$ and no multivalent cations to favor
$\mathrm{HP}$, and with $100 \mathrm{mM} \mathrm{KCl}$ and $5 \mathrm{mM}\left[\mathrm{Co}\left(\mathrm{NH}_{3}\right)_{6}\right]^{3+}$ to favor PK. HPMut was mapped in $100 \mathrm{mM} \mathrm{KCl}$ with $10 \mathrm{mM} \mathrm{MgCl}_{2}$. $\mathrm{PK}$ and HP/HPMut share structural motifs P1, P2, and junction J1/2 (Fig. 3). The differences between the two conformations are the $\mathrm{P} 0$ and $\mathrm{P} 3{ }^{\prime}$ motifs in $\mathrm{PK}$ and the $\mathrm{P} 3$ stem-loop in HP/HPMut. Enzymatic mapping used RNase T1 (cleaves after unpaired G), RNase A (cleaves after unpaired C and $\mathrm{U}$ ), and RNase $\mathrm{I}_{\mathrm{f}}$ (cleaves after any single stranded nucleotide). Chemical mapping used DMS (methylates N1 of A and $\mathrm{N} 3$ of $\mathrm{G}$ when unpaired), CMCT (modifies N3 of $\mathrm{U}$ and $\mathrm{N} 1$ of $\mathrm{G}$ when unpaired), and DEPC (modifies an exposed N7 of A) [33]. $\mathrm{Pb}^{2+}$ cleavage [34,35] and SHAPE mapping [36] were used to identify flexible regions.

In $5 \mathrm{mM}\left[\mathrm{Co}\left(\mathrm{NH}_{3}\right)_{6}\right]^{3+}$, where $\mathrm{PK}$ dominates, the $\mathrm{P} 0$ stem region, which incorporates the $3^{\prime}$ splice site, is not reactive (Fig. 3A). Of the three nucleotides that bridge $\mathrm{P} 0$ and $\mathrm{P} 1, \mathrm{~A} 687$ is modified by SHAPE and A688 is modified by DMS. There are no strong hits on the $\mathrm{Pl}$ hairpin. Reactivity is clustered in the $\mathrm{J} 1 / 2$ junction and the $5^{\prime}$ end of the $\mathrm{P} 3^{\prime}$ hairpin. The $\mathrm{J} 1 / 2$ junction is cleaved by RNase $\mathrm{I}_{\mathrm{f}}, \mathrm{Pb}^{2+}$ and modified by SHAPE and DMS. The $\mathrm{P}^{\prime}$ ' hairpin is quite sensitive to enzymatic cleavage, but less so towards small molecules. RNases $\mathrm{I}_{\mathrm{f}}, \mathrm{T} 1$, and A cleave along the 5' end of P3', whereas the loop region is modified by DEPC at A724 and $\mathrm{A} 730$. $\mathrm{PK}$ is largely protected from $\mathrm{Pb}^{2+}$ cleavage (Fig. 4A,B). After incubation in $\mathrm{Pb}(\mathrm{OAc})_{2}$ for $4 \mathrm{~min}$, strong cleavage only occurs at the J1/2 junction, particularly at A704 (Fig. 4B). 
A

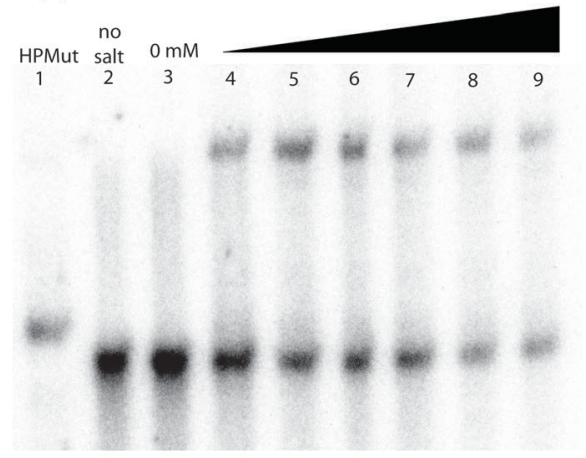

B

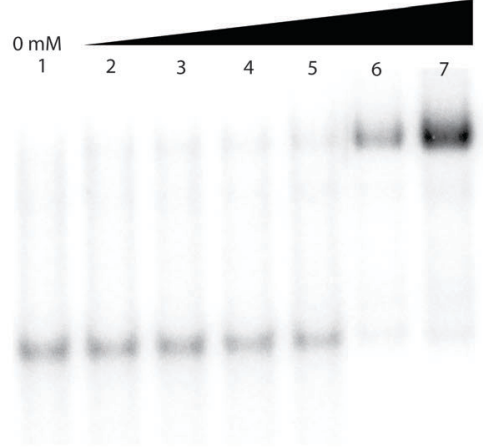

Figure 2. Native gels of 3PSS and HPMut under various conditions. (A) First lane is HPMut folded with $10 \mathrm{mM} \mathrm{Tris} \mathrm{(pH7),} 100 \mathrm{mM} \mathrm{KCl}$, and $10 \mathrm{mM} \mathrm{MgCl}$; the second lane is 3PSS with $10 \mathrm{mM}$ Tris $(\mathrm{pH} 7)$ and no monovalent or divalent ions. The remaining lanes are for 3 PSS with $10 \mathrm{mM}$ Tris $(\mathrm{pH} 7)$ and $100 \mathrm{mM} \mathrm{KCl}$ with increasing $\mathrm{Mg}^{2+}$ concentration $(0,2.5,5.0,7.5,10,15$, and $25 \mathrm{mM})$. (B) First lane is $3 \mathrm{PSS}$ with $10 \mathrm{mM}$ Tris (pH7), $100 \mathrm{mM}$ $\mathrm{KCl}$ and no multivalent ions. The remaining lanes are 3 PSS with $10 \mathrm{mM}$ Tris $(\mathrm{pH} 7)$ and $100 \mathrm{mM} \mathrm{KCl}$ with increasing $\left[\mathrm{Co}\left(\mathrm{NH}_{3}\right)_{6}\right]^{3+}$ concentration $(0.002$, $0.01,0.02,0.1,2.5$, and $5 \mathrm{mM}$ ).

doi:10.1371/journal.pone.0038323.g002

Medium cleavage occurs at the loop of P3' (Fig. 4 and Fig. S1A). Even after $60 \mathrm{~min}$ of incubation, $\mathrm{PK}$ is un-reactive outside these regions (Fig. 4A,B).

In the absence of multivalent cations, where HP dominates, $\mathrm{P} 1$ has many enzymatic cleavages and small molecule modification sites (Fig. 3B and $\mathrm{S} 1$ ). The $\mathrm{J} 1 / 2$ junction of $\mathrm{HP}$ is reactive with most reagents, particularly including DEPC. The loop of the $\mathrm{P} 3$ hairpin is sensitive to RNase T1, DMS, SHAPE, and DEPC. There is a strong DEPC modification at the A730 bulge. After a 4 min incubation in $\mathrm{Pb}(\mathrm{OAc})_{2}$, $\mathrm{HP}$ has a strong $\mathrm{Pb}^{2+}$ cleavage after G703 in J1/2 (Figs. 3B and 4B). After 8 min of incubation in $\mathrm{Pb}(\mathrm{OAc})_{2}, \mathrm{HP}$ is cleaved at nearly every nucleotide (Fig. 4A).
Though reactivity with $\mathrm{Pb}^{2+}$ is widespread, the most intense cleavage (G703) has only about $67 \%$ the highest intensity observed in PK or HPMut (Fig. 4B).

3PSS folded in $10 \mathrm{mM} \mathrm{Mg}^{2+}$ yields both $\mathrm{HP}$ and PK in roughly equal amounts (Fig. 2A lane 7). 3PSS folded under these conditions was also probed (Fig. S1E). The reactivity observed under these conditions is consistent with both PK and HP being present. This, along with the native gel analysis, verifies the presence of both conformations when 3PSS folds in the presence of $\mathrm{Mg}^{2+}$.

To further test the presumed hairpin secondary structure, mapping was also carried out on HPMut in the presence of

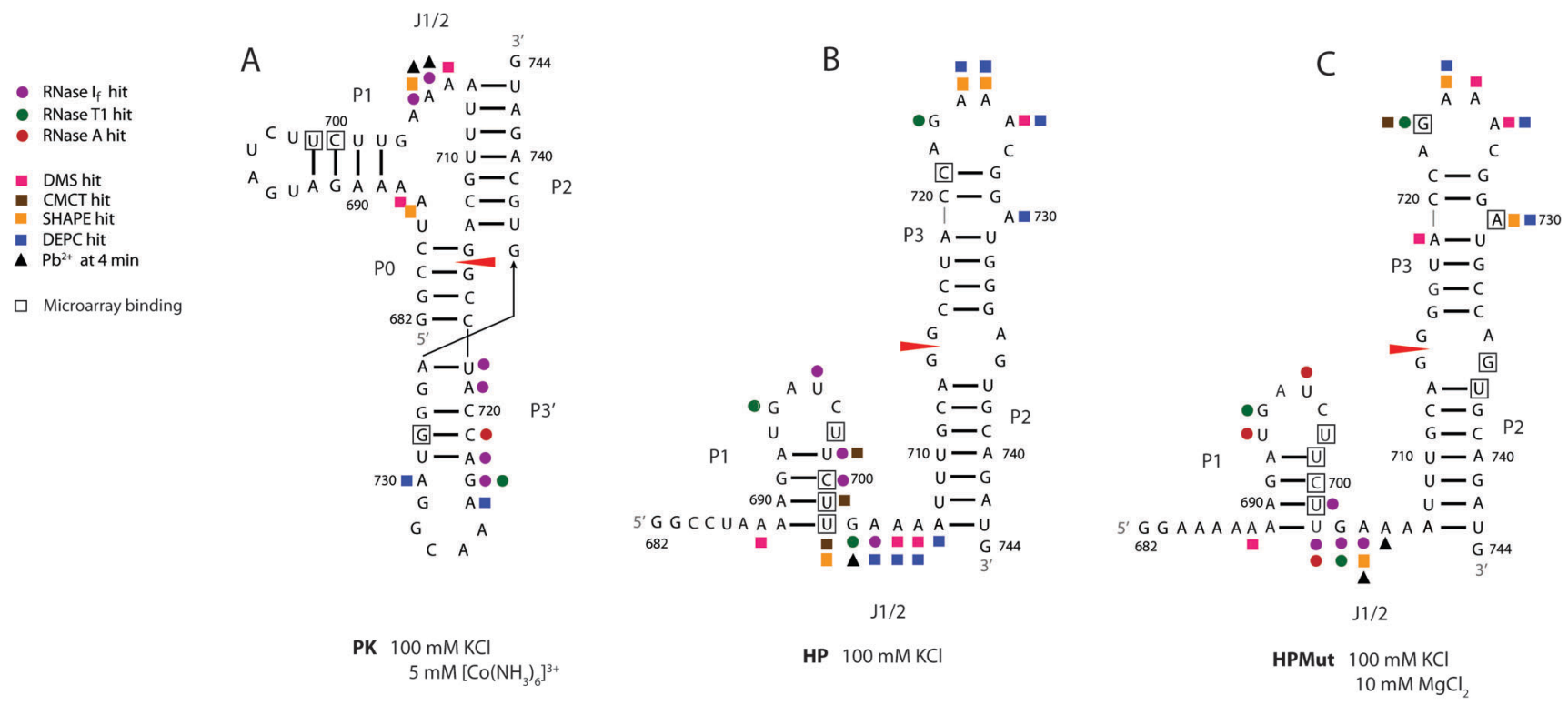

Figure 3. Mapping results for 3 PSS and HPMut. The reagents are indicated by shape and color (see figure key). Only strong hits, with $\geq 2 / 3$ the highest intensity band in a lane after subtraction of intensity from the control lane, are annotated. $\mathrm{Pb}^{2+}$ mapping results are taken from 4 min incubation time. For $\mathrm{Pb}^{2+}$, strong hits had $\geq 2 / 3$ the intensity of A704 from PK, the strongest band observed under any condition at 4 min incubation time. Boxed residues are the center nucleotide of sites binding strongly ( $\geq 1 / 3$ the highest intensity spot) and unambiguously to microarray probes (i.e. without alternative binding sites capable of forming stable duplexes within $3 \mathrm{kcal} / \mathrm{mol}$ of the optimal binding site). All folding buffers contained $10 \mathrm{mM}$ Tris (pH7), $100 \mathrm{mM} \mathrm{KCl}$. (A) Mapping results for 3 PSS folded in $5 \mathrm{mM}\left[\mathrm{Co}\left(\mathrm{NH}_{3}\right)_{6}\right]^{3+}$ (PK). (B) Mapping results for $3 \mathrm{PSS}$ folded without $\mathrm{Mg}{ }^{2+}$ or $\left[\mathrm{Co}\left(\mathrm{NH}_{3}\right)_{6}\right]^{3+}(\mathrm{HP})$. RNase A reactivity is not annotated because RNA is over-digested at the same enzyme concentration that yielded good results in PK and HPMut (Fig. S3). (C) Mapping results for HPMut folded in $10 \mathrm{mM} \mathrm{Mg}^{2+}$.

doi:10.1371/journal.pone.0038323.g003 

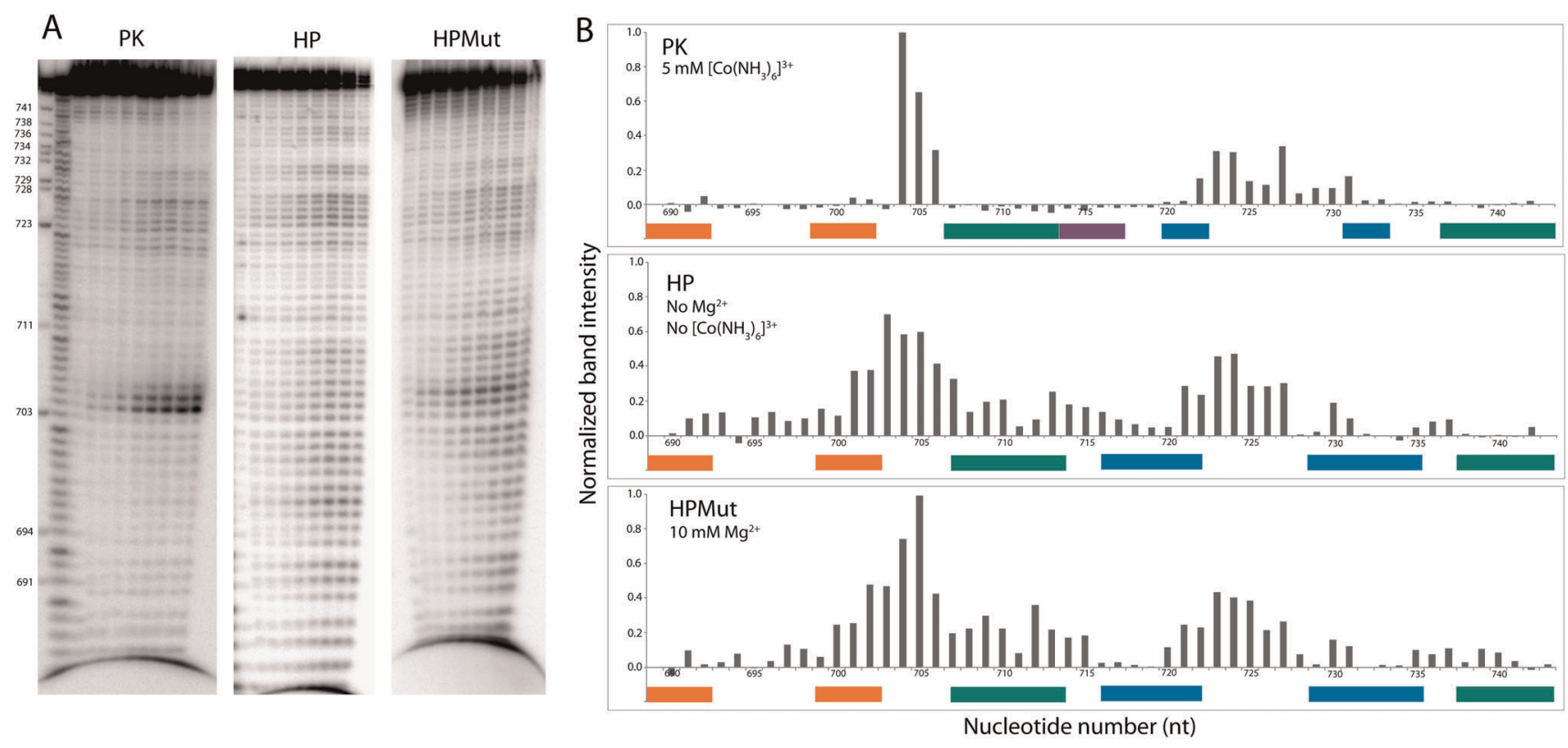

Figure 4. $\mathrm{Pb}^{2+}$ mapping results. (A) Gel images of $\mathrm{PK}\left(5 \mathrm{mM}\left[\mathrm{Co}\left(\mathrm{NH}_{3}\right)_{6}\right]^{3+}\right), \mathrm{HP}$ (no multivalent ions), and $\mathrm{HPMut}\left(10 \mathrm{mM} \mathrm{Mg} \mathrm{g}^{2+}\right)$ incubated with $1 \mathrm{mM} \mathrm{Pb}(\mathrm{OAc})_{2}, 10 \mathrm{mM}$ Tris ( $\mathrm{pH}$ 7), and $100 \mathrm{mM} \mathrm{KCl}$ for 0, 0.5, 1, 2, 4, 8, 15, 30, and $60 \mathrm{~min}$. (B) integrated band densities at each nucleotide normalized to the strongest band observed under any condition (A704 from PK) at 4 min incubation time. RNA structure is annotated below each graph where paired nucleotides that form complementary helical strands are indicated by colored boxes. doi:10.1371/journal.pone.0038323.g004

$10 \mathrm{mM} \mathrm{Mg}^{2+}$ (Fig. 3C). The P1 hairpin has strong RNases $\mathrm{I}_{\mathrm{f}}, \mathrm{T} 1$, and A cleavage sites. There is also a DMS modification at A688, similar to HP. The J1/2 junction has RNases $\mathrm{I}_{\mathrm{f}}$ and $\mathrm{T} 1$ cleavages and SHAPE and $\mathrm{Pb}^{2+}$ modification sites. A719 in the AU pair flanking the A730 bulge is modified by DMS. The loop of P3 is modified strongly by DMS, CMCT, SHAPE, and DEPC and also cleaved by RNase T1. SHAPE and DMS modify the A730 bulge. When normalized by the most intense cleavage in PK (A704), the $\mathrm{Pb}^{2+}$ cleavage pattern for HPMut is similar to that seen for HP, but the single dominant cleavage is at A705 (Figs. 3C and 4B). After $15 \mathrm{~min}$ of incubating in $\mathrm{Pb}(\mathrm{OAc})_{2}$, HPMut is cleaved at nearly every nucleotide (Fig. 4A). HPMut folded in $100 \mathrm{mM} \mathrm{KCl}$ and $5 \mathrm{mM}\left[\mathrm{Co}\left(\mathrm{NH}_{3}\right)_{6}\right]^{3+}$ was also probed with RNAse A, T1, and $\mathrm{Pb}^{2+}$; results were similar to those with $100 \mathrm{mM} \mathrm{KCl}$ and $10 \mathrm{mM}$ $\mathrm{Mg}^{2+}$ (Fig. S1C).

\section{Accessibility to Short Oligonucleotides}

PK, HP, and HPMut were hybridized to microarrays with 861 chimeric pentamer and hexamer oligonucleotides containing $2^{\prime}$ O-methyl RNAs with locked nucleic acid (LNA) and 2,6diaminopurine modifications at selected positions to roughly equalize the thermodynamic stability of hybridization to unstructured RNA [37,38,39,40]. Results for probes with five consecutive nucleotides Watson-Crick complementary to 3PSS are listed in Table S1. Hairpin Pl is strongly bound under all conditions tested (Fig. 3). The probes invade more of the Pl stem in HP and HPMut than in PK, however. PK also strongly binds to a probe that invades the $\mathrm{P} 3^{\prime}$ helix (Fig. 3A). HPMut strongly binds to probes centered at the bulged A730 of P3 (Fig. 3C) and at G736 and U737 on one side of the internal loop that contains the $3^{\prime}$ splice site.

\section{Secondary Structure is Conserved}

Based on the structure probing experiments and the expanded sequence alignment used in this study (Table S2), small changes are proposed for the model versus the one previously proposed [10]. The changes in the structures are shifting of nucleotides in P1 (the bioinformatics model had C700 bulged) and the revised pairing of A713 to U737 in the pseudoknot, which grew $\mathrm{P} 2$ at the expense of P0 (Fig. 1). A base pair is also added between U718 and A735 in P3'. The hairpin and pseudoknot were initially presented as alternative secondary structures, but both are observed in solution (Fig. 2).

Both conformations of the $3^{\prime}$ splice site are well conserved throughout the alignment of all unique Influenza A sequences. All helices are greater than $92 \%$ conserved and canonical pairing, on average, is $95 \%$ conserved (Table S2). Every helix has at least one consistent or compensatory mutation (Fig. 5). When mutations led to non-canonical pairs, they were most often CA $(2.9 \%)$ or GA pairs $(1.3 \%)$. These CA and GA pairs occur mainly in the middle of helices: e.g. pair 691-700 in P1, 711-739 in P2, and 720-729 in P3 (Fig. 5, Table S2). Other types of non-canonical pairs were rarely observed (Table $\mathrm{S} 2$ ).

\section{Base Pair and GC Pair Content Correlates with Host Species}

On average, the pseudoknot structures expected to be most stable have 18 canonical base pairs, $50 \%$ of which are GC pairs (Table S3). The structures expected to be least stable have, on average, 16 canonical base pairs and only $31 \%$ of them are GC pairs. When clustered by the fraction of GG pairs and canonical pairs, five groups are apparent (Fig. 6). The number of unique sequences that fall within each cluster follows a bell-shaped distribution (Fig. 6). The stable clusters have sequences that allow for a greater number of canonical pairs and, in particular, GC pairs. For example, across all unique sequences, positions 684 and 715 are most often UG pairs, but in the stable clusters they are primarily CG pairs. Conversely, the less stable clusters are comprised of sequences that do not allow for as many canonical and GC pairs. Positions 711 and 739, for example, 

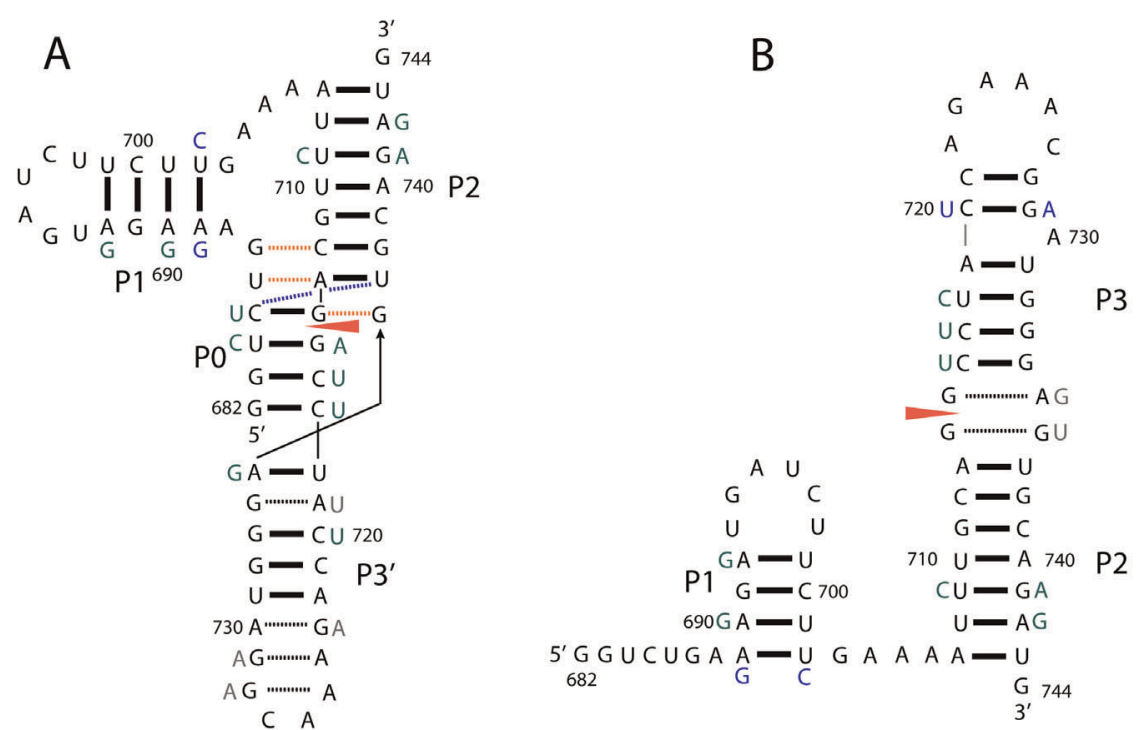

Figure 5. Consensus sequence and structure. (A) PK and (B) HP. Canonical pairs are indicated with solid bars and putative non-canonical pairs with dashed lines. Stem mutations that preserve base pairing are colored green for single (consistent) point mutations and blue for double (compensatory) point mutations when they occur in five or more sequences. Mutations with implications for non-canonical pairs are indicated in grey. Potential base triples are indicated with orange dashed lines. The exact interaction between the base pair and loop residue, however, cannot be inferred from available data. Putative helical stacking is indicated with a blue dashed line.

doi:10.1371/journal.pone.0038323.g005

most often form a GC pair; in the less stable strains, however, these positions are mostly AC pairs (Table S2). The hairpin structure metrics globally follow that of the pseudoknot (Table S3).

The fraction of GC and canonical pairs in the pseudoknot and hairpin structures correlates with the fraction of influenza A sequences that infect a given host species (Fig. 6 and Table S3). Avian strains make up $82 \%$ of the most GC and base pair rich sequences, but only $26 \%$ of the sequences with lower content. The opposite trend holds for sequences that infect humans and swine: only $9 \%$ of the most GC and base pair rich sequences infect humans (another $9 \%$ for swine), while $48 \%$ of the sequences with lower base pair and GC content are human specific $(23 \%$ are swine specific; Fig. 6).

\section{Discussion}

Influenza remains a public health problem [41] and is also a potential agent for bioterrorism $[42,43,44]$. Current therapeutics target influenza proteins [45]. RNA, which is used throughout influenza replication, is an attractive alternative target. The results presented here show that a fragment of influenza A segment 7 can fold into two different conformations: a hairpin, HP, and a pseudoknot, PK. The predicted free energies of HP and PK are $-16.9 \mathrm{kcal} / \mathrm{mol}$ and $-16.3 \mathrm{kcal} / \mathrm{mol}$, respectively. This small difference in free energy predicts that the equilibrium constant for the two conformations is close to 1 . Both conformations have significant concentrations when $\mathrm{Mg}^{2+}$ is present (Fig. 2), consistent with the predicted free energy difference between them. Stabilizing the free energy by as little as $1.5 \mathrm{kcal} / \mathrm{mol}$, which can be supplied by one or two hydrogen bonds, will shift the equilibrium constant by a factor of 10 . Thus, small perturbations, such as protein binding, can push the equilibrium to one conformation. Switching between HP and PK may have a role in the regulation of splicing and this suggests that these RNA structures have potential as therapeutic targets.

\section{Conformational Switching has Implications for Function}

The presence of two conformations has implications for function, as each conformation places several functional elements in different structural contexts. In 3PSS, the pseudoknot may make the sequences required for molecular recognition inaccessible to splicing elements; whereas, in the hairpin conformation, these elements are less constrained by structure and are presumably better able to interact with splicing factors. The most obvious case is sequestration of the splice site in $\mathrm{P} 0$ of $\mathrm{PK}$ versus exposing it in a two-by-two nt internal loop in HP. A similar equilibrium between hairpin and pseudoknot structures occurs within the $3^{\prime}$ splice site of segment 8 of influenza $\mathrm{A}$ and $\mathrm{B}$ and has been proposed to play a role in the regulation of splicing $[16,17]$. The segment 8 structures are different, but also place the splice site in paired or unpaired structural contexts, potentially modulating splicing by hiding or revealing the splice site. This may be a common mechanism to control splicing: For example, sequestration of cryptic $3^{\prime}$ splice sites in pseudoknots of the yeast actin mRNA [46] and Sd.cob,1 group I intron [47] acts to suppress splicing at these sites.

The region surrounding the $3^{\prime}$ splice site of segment 7 also contains the key residues of the SF2/ASF exonic splicing enhancer binding site in the purine rich stretch from nucleotides 723 to 738 [11]. These residues form different hairpins, P3 and P3', in HP and PK, respectively (Fig. 1). Additionally, a polypyrimidine tract occurs at nucleotides 696 to 702, which form the $3^{\prime}$ half of hairpin $\mathrm{P} 1$. In the absence of multivalent cations $\mathrm{Pl}$ is extremely reactive, including stem positions, indicating that $\mathrm{P} 1$ may be particularly unstable (Fig. 3B). Roles for splice site RNA structure in regulating splicing, e.g. by hiding and revealing splice sites or protein binding sites, have been described for other RNAs [48]. In particular, RNA conformational switching can be induced by proteins $[49,50]$ or small molecules $[51,52]$ to regulate splicing. Expression of M2 protein is known to occur late in viral infection [15]. Perhaps changes in the cellular environment over time: such as $\mathrm{pH}$, protein binding, or the presence of metabolites could affect the $3^{\prime}$ splice 


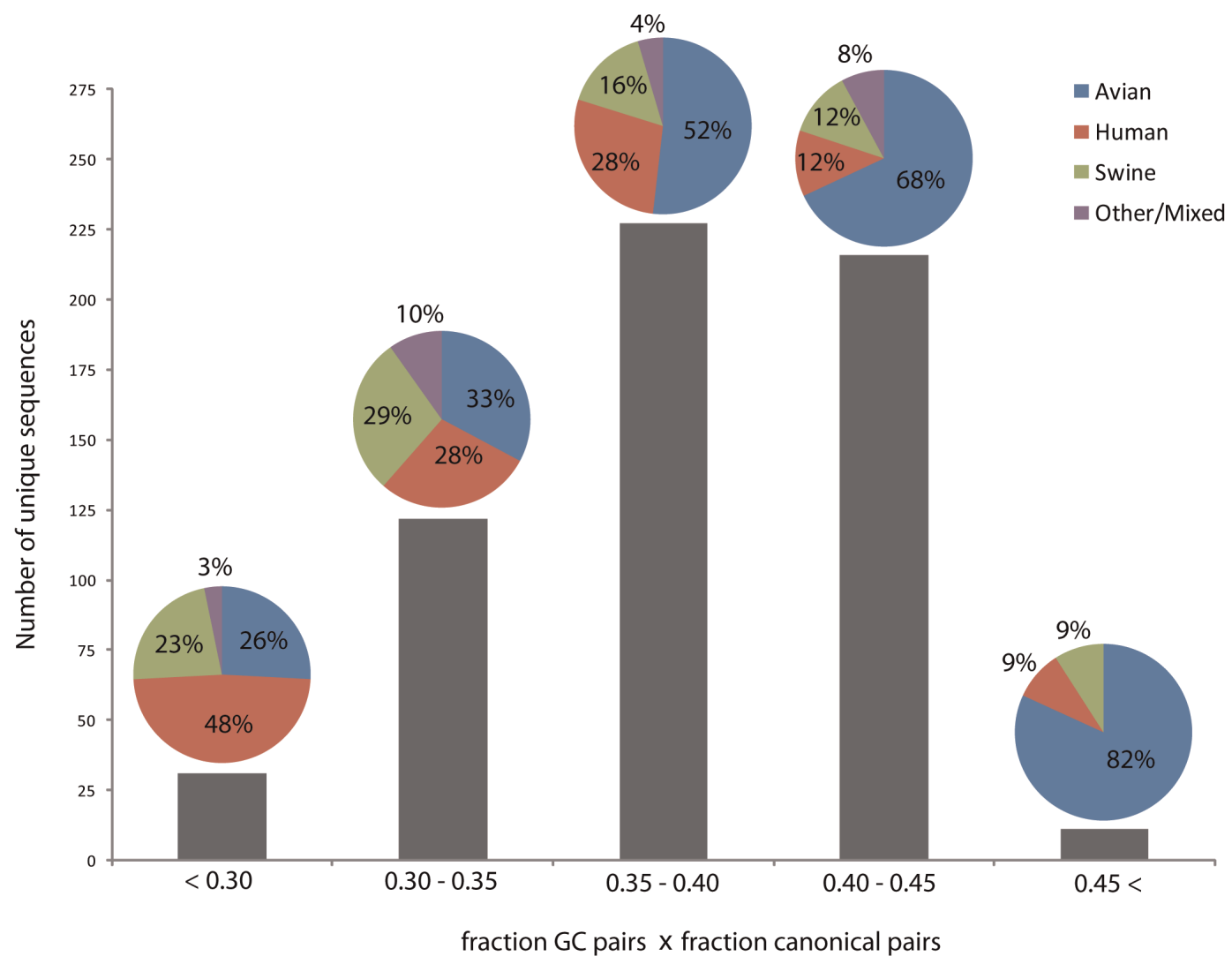

Figure 6. Histogram of all unique influenza A sequences grouped by expected stability of pseudoknot mutations. The stability metric is calculated as the fraction of nucleotides that are canonically paired, multiplied by the fraction of GC pairs. Above each bar is a pie chart that gives the percentage of sequences that infect a given host. Other/Mixed strains are those where the majority of sequences infected an animal from other than human, swine, or avian species; or where they could infect more than one type of host species.

doi:10.1371/journal.pone.0038323.g006

site structure to make this region more accessible and contribute to increased production of M2 mRNA.

Increased $\mathrm{Mg}^{2+}$ allows for some pseudoknot folding, but even $25 \mathrm{mM} \mathrm{Mg}^{2+}$ cannot push the equilibrium completely to pseudoknot (Fig. 2A). Addition of $\left[\mathrm{Co}\left(\mathrm{NH}_{3}\right)_{6}\right]^{3+}$, however, preferentially stabilizes the 3PSS pseudoknot (Fig. 2B). Preferable binding of $\left[\mathrm{Co}\left(\mathrm{NH}_{3}\right)_{6}\right]^{3+}$ to pseudoknots over hairpins by 3 to 5 fold has been described $[53,54]$. Compared to hexahydrated magnesium, $\left[\mathrm{Co}\left(\mathrm{NH}_{3}\right)_{6}\right]^{3+}$ has a similar size but a higher charge density, allowing for stronger interactions with RNA [55,56]. The particular affinity of $\left[\mathrm{Co}\left(\mathrm{NH}_{3}\right)_{6}\right]^{3+}$ to pseudoknots has been attributed to the tendency of pseudoknots to have pockets of high negative charge at the intersection of adjacent pseudoknot helices and/or connecting loops [53]. NMR studies on a viral frameshift pseudoknot showed that $\left[\mathrm{Co}\left(\mathrm{NH}_{3}\right)_{6}\right]^{3+}$ binds tightly to a divalent metal binding pocket formed by a two nucleotide loop and the major groove of a nearby helix [54].

Cobalt hexamine is also able to bind motifs containing GA pairs and can do so more strongly than $\mathrm{Mg}^{2+}$ [57]. Interestingly, one of the distinguishing features of the 3PSS pseudoknot is the possibility of forming multiple GA pairs in $\mathrm{P}^{\prime}$ ': a single GA within the P3' helix, and three tandem GA pairs in the terminal loop (Figs. 3A and $5 \mathrm{~A}$ ). When mutations occur in this loop, they are most often to another purine base (Fig. 5A and Table S2). Evidence for the strength of the interaction between $\mathrm{PK}$ and $\left[\mathrm{Co}\left(\mathrm{NH}_{3}\right)_{6}\right]^{3+}$ can be inferred from the strong stops observed in primer extension on 3PSS folded in $\left[\mathrm{Co}\left(\mathrm{NH}_{3}\right)_{6}\right]^{3+}$ (Fig. S2 lanes 5 to 8 ). Even though samples were washed in $70 \%$ ethanol and heated to $90^{\circ} \mathrm{C}$, the reverse transcriptase is unable to read through the strong secondary structure of $\mathrm{P}^{\prime}$ stabilized by the remaining $\left[\mathrm{Co}\left(\mathrm{NH}_{3}\right)_{6}\right]^{3+}$.

\section{Implications from Results of Mapping RNA Structures}

$\mathrm{Pl}$ is more accessible to enzymes in HP and HPMut than in PK. Even at low RNase $\mathrm{I}_{\mathrm{f}}$ concentrations $\mathrm{Pl}$ is reactive in $\mathrm{HP}$ (Fig. 3B and Fig. S3 lane 5). At medium enzyme concentration, HP is extremely reactive in the $\mathrm{P} 1$ region (Fig. S3 lane 4). Conversely, $\mathrm{P} 1$ of $\mathrm{PK}$ is not strongly reactive, even in the loop region, at the highest enzyme concentration (Fig. 3A and Fig. S3 lane 15). Additionally, the loop of $\mathrm{Pl}$ in $\mathrm{PK}$ is not strongly reactive with RNase A and T1, but is strongly reactive in HPMut (Fig. 3). This difference is unlikely to arise from changes in buffer: HPMut folded in $5 \mathrm{mM}\left[\mathrm{Co}\left(\mathrm{NH}_{3}\right)_{6}\right]^{3+}$ also has a strong RNase A and T1 cleavage in the $\mathrm{P} 1$ loop (Fig. S1C). HP is extremely reactive to RNAse $\mathrm{A}$ in the $\mathrm{Pl}$ region: at even the lowest enzyme concentration it is mostly degraded (Fig. S3 lane 8). These results indicate that $\mathrm{Pl}$ might be less accessible to proteins, such as splicing factors, in the pseudoknot conformation, but more accessible in the hairpin structure. $\mathrm{P} 1$ is expected to be less stable in $\mathrm{HP}$ than in PK because the ends are unrestricted upon P1 unfolding in HP. This provides a more favorable entropy change for unfolding in HP than in PK. In general, an open, flexible, polypyrimidine tract is better able to bind splicing factors [49,58]. Interestingly, $\mathrm{Pl}$ of HPMut is reactive to RNase $\mathrm{V} 1$, which cleaves double stranded or stacked RNA, and also to reagents that are 
specific to single stranded RNA (Fig. S1D). In particular, U701 is strongly hit by both RNAse $\mathrm{I}_{\mathrm{f}}$ and $\mathrm{V} 1$. These results suggest that the base pairs in Pl of HPMut are dynamic and may be "breathing." This suggests the same dynamics for HP, although this cannot be directly proven because V1 requires $\mathrm{Mg}^{2+}$.

A striking feature of the $\mathrm{Pb}^{2+}$ cleavage results (Fig. 4) is the dramatic difference in reactivity for PK compared to HP and HPMut. In general, $\mathrm{PK}$ is much less reactive to $\mathrm{Pb}^{2+}$, except in J1/ 2. This effect does not appear to be due to competition between $\mathrm{Pb}^{2+}$ and the $\left[\mathrm{Co}\left(\mathrm{NH}_{3}\right)_{6}\right]^{3+}$ used to fold PK; HPMut, when folded in $5 \mathrm{mM}\left[\mathrm{Co}\left(\mathrm{NH}_{3}\right)_{6}\right]^{3+}$ has wide-spread reactivity (Fig. S1C) that is more similar to $\mathrm{HP}$ in $100 \mathrm{mM} \mathrm{KCl}$. The strongest $\mathrm{Pb}^{2+}$ cleavages are in the $\mathrm{J} 1 / 2$ regions of $\mathrm{PK}$ and HPMut: specifically at A704 and A705 of PK and HPMut, respectively (Fig. 4B). J1/2 of $\mathrm{HP}$ is also sensitive to $\mathrm{Pb}^{2+}$ cleavage, yet there are no cleavages as intense as in PK or HPMut. Perhaps when the RNA is folded in the absence of multivalent cations (HP) a specific binding pocket for lead, such as in tRNA [59] and in a group I intron [60], may no longer form. DEPC modifies the N7 position of adenosine, which can participate in tertiary contacts. Notably, J1/2 in HP is strongly reactive to DEPC but J1/2 is not strongly reactive in PK and HPMut where multivalent ions are present. This provides further evidence for a potential tertiary fold for $\mathrm{J} 1 / 2$.

Except for the RNase T1 hit at G723, the loop of P3 in HP and HPMut is insensitive to enzymes, but quite reactive with small molecules (Fig. 3B and C and Fig. S1B, C, and D). Reactivity in the P3 helix is confined to the bulge loop at A730, and a single DMS hit at A719 of HPMut, where A719 is paired, but in a weak structural context. In contrast, $\mathrm{P} 3^{\prime}$ is very sensitive to enzyme cleavage (Fig. 3A and Fig. S1A). An unusual feature of P3' is that the greatest reactivity occurs at the $5^{\prime}$ side of the hairpin and includes three residues involved in base pairs (Fig. 3A). P3' has fewer stretches of canonical pairs than any other region of $\mathrm{PK}$ as well as several putative non-canonical pairs (Fig. 5A). P3' may be structurally dynamic. Indeed, breaking base pairs in P3' would be necessary to transition to the hairpin conformation. This structure may be tuned to easily open and facilitate conformational switching.

It may be possible to target either or both of the conformations of 3PSS with short oligonucleotides in order to modulate biological function or for potential therapeutic applications. The results of oligonucleotide microarray mapping show that the hybridization behavior of PK, HPMut and HP are distinct (Fig. 3, Fig. S1, and Table S1). Though the binding results are influenced by buffer conditions, which are not physiological, the strong binding centers for the probes suggest regions for targeting with oligonucleotides. The small hexamer and pentamer binding sites may be used as nucleation sites for the binding of larger oligonucleotides such as siRNAs [61] or shRNAs [62].

\section{Conservation of Structure}

The HP and PK conformations are well conserved throughout influenza A strains. They span a region that is under strict selective pressure: it must maintain open reading frames for $\mathrm{Ml}$ and, after nt 714 , the M2 protein open reading frame, as well as protein binding sites [11]. Mutations must also maintain RNA secondary structure (Fig. 5). Conservation is also favored by the influenza encoded polymerase, which has higher fidelity than most viral polymerases [63]. The high conservation of structure in the region containing the $3^{\prime}$ splice site of segment 7 makes this region an attractive therapeutic target. Moreover, the presence of small loops favors approaches for rational selection of molecules as lead compounds [28,29,31]. The microarray results (Fig. 3 and Table $\mathrm{S} 1)$ suggest that short oligonucleotides may also be used to inhibit correct splicing. Similarly, the M1 protein amino acids encoded by 3PSS may be attractive targets for antiviral agents, as their evolution is also strictly constrained by the need to maintain functional sites and structure in both the protein and RNA.

Mutations from canonical to non-canonical pairs in the 3PSS region are rare (Table S2). When they occur they are in the middle of stems, where they might be less disruptive to structure. Indeed, only two types of non-canonical pairs have significant numbers at sites predominantly canonically paired (Table S2): CA pairs, which can maintain A form helices [64], followed by GA pairs, which can substitute for canonical pairs in phylogenetically conserved structures $[65,66,67]$. Conversely, at sites where putative noncanonical pairs predominate, mutations occur most often to form canonical pairs or other putative non-canonical interactions (Fig. 5 and Table S2). For example: in P3', nucleotides 719 and 734 are most often AG, but the most frequently observed mutation converts this to a UG pair (Fig. 5A and Table S2). Imino AG and canonical UG pairs both present an amino group in the minor groove, which can be used for molecular recognition [68,69,70]. Three consecutive GA pairs are possible in the terminal loop of P3' (Fig. 5A). When mutations occur they maintain purines at each side of the helix. This sequence pattern is common in internal loops, where it results in three consecutive purine-purine sheared pairs [71]. In HP the two-by-two nucleotide internal loop may contain non-canonical interactions as well. G736 frequently changes to a $\mathrm{U}$, allowing it to pair with G714 (Fig. 5B) and positions 715 and 735 are always purines: GA or GG, which have been observed to form interactions in other RNAs [72,73]. Interestingly, internal loops comprised of GG and GA are observed in the ribosomal loop E motif [74] and in the HIV-1 Rev protein binding element [75]; in both cases the loop plays important roles in protein recognition.

Another conserved feature in the structural model and alignment (Fig. 5A and Table S4) is the possibility of forming base triples at G687(C712-G738), U686(A713-U737) and (C685G714)G736 in PK. UAU and CGG are the most common base triples in known 3D structures of RNA [76]. Sequence variations at these positions could maintain potential triple interactions (Table S4). Because of the close proximity of stems and loops, such loop-helix interactions are commonly found in pseudoknots $[77,78,79]$ and can play important roles in stabilizing structure [80]. These putative triples occur at the intersection of the P0 and P2 pseudoknot helices, which may form a coaxial stacking interaction where G714 is stacked on A713 and U737 is stacked on C685 (Fig. 5A). The same type of stacking interaction, where pseudoknot helices coaxially stack with AU on CG, is observed in a bacteriophage mRNA pseudoknot $[81,82]$.

Host species distribution of number of canonical pairs and GG pair content. 3PSS sequences segregated into five groups based on their canonical base pair and GC pair content. The composition of each cluster varied dramatically by the host specificity of the influenza A strain (Fig. 6): the greater the strength of the structure, as gauged by the overall base pair density and number of GC pairs, the higher the fraction of avian vs. human strains. The swine specific strains fell somewhere between human and avian. These trends may be explained by the temperatures encountered where influenza replicates. Temperatures for the avian gut, swine and human respiratory tract are $41^{\circ} \mathrm{C}, 37^{\circ} \mathrm{C}$, and $33^{\circ} \mathrm{C}$, respectively [83]. Perhaps the higher number of canonical and GC pairs in avian strains occurs to maintain the pseudoknot and hairpin structures, or their ratio, at higher temperatures. Conversely, at the lower temperatures found in swine and human hosts, there is less pressure to stabilize these structures. The host specificity of the observed changes in the $3^{\prime}$ splice site region may 
be a local instance of a global trend in influenza A RNA structural stability. A study of all available influenza A coding regions found that there were global trends in RNA folding free energy and, in general, avian sequences were more stable than swine or human [84]. Additionally, four of the eight influenza A segments, including segment 7, showed evidence for globally conserved RNA secondary structure [84]. Interestingly, the strength of this global structure also favored avian sequences.

\section{Methods}

\section{Production of 3PSS and HPMut RNAs}

DNA templates for 3PSS and HPMut RNAs, including T7 promoter sites were ordered from IDT Inc. The 3PSS sequence was selected from the GC pair rich cluster and is found in four avian sequences of mixed strains (GenBank accessions: CY081301, CY021470, CY014592, DQ107463). HPMut has an identical sequence except where mutations were introduced to abolish the pseudoknot: positions 684-6 (mutated to unpaired adenosines) and 716-7/733-4 (two hairpin GG pairs swapped to GG). In vitro transcription reactions were performed using an Ampliscribe T7Flash Transcription kit (Epicentre). Products were purified by denaturing PAGE and electroeluted in a Bio-Rad Model 422 electro-eluter. RNAs were $5^{\prime}$ end labeled with $\gamma-{ }^{32} \mathrm{P}$ ATP (Perkin Elmer), then re-purified by denaturing PAGE.

\section{RNA Folding for Native Gel Analysis}

For each sample, about 100,000 cpm of $5^{\prime}$ end labeled RNA was heated in water to $90^{\circ} \mathrm{C}$ for $2 \mathrm{~min}$ and slowly cooled to $50^{\circ} \mathrm{C}$ in a thermocycler. Tris and $\mathrm{KGl}$ were added to a final concentration of $10 \mathrm{mM}$ Tris $(\mathrm{pH} \mathrm{7})$ and $100 \mathrm{mM} \mathrm{KCl}$, at $50^{\circ} \mathrm{C}$, for all samples. To study the multivalent cation dependent folding of $3 \mathrm{PSS}, \mathrm{MgCl}_{2}$ was added to get a range of final concentrations from 2.5 to $25 \mathrm{mM}$ and, in separate samples without $\mathrm{Mg}^{2+},\left[\mathrm{Co}\left(\mathrm{NH}_{3}\right)_{6}\right] \mathrm{Cl}_{3}$ was added to span 0.002 to $5 \mathrm{mM}$. HPMut was folded with a final concentration of $10 \mathrm{mM} \mathrm{MgCl}_{2}$ or $5 \mathrm{mM}\left[\mathrm{Co}\left(\mathrm{NH}_{3}\right)_{6}\right]^{3+}$ at $50^{\circ} \mathrm{C}$. All samples were then slow cooled from $50^{\circ} \mathrm{C}$ to $37^{\circ} \mathrm{C}$ where they remained for 15 min before placing them on ice. Folding was analyzed by native gel electrophoresis. Glycerol loading buffer $(3 \mu \mathrm{L})$ was added to each sample and about 20,000 cpm of folded RNA ( $2 \mu \mathrm{L})$ was run per lane on a non-denaturing $6 \%$ polyacrylamide gel made with $1 \mathrm{X}$ THEM (34 mM Tris Base, $57 \mathrm{mM}$ HEPES, $0.1 \mathrm{mM}$ EDTA, $10.0 \mathrm{mM} \mathrm{MgCl}_{2}$ ) buffer. The gel was run using $1 \times$ THEM running buffer, at low Wattage $(15 \mathrm{~W})$, at $4{ }^{\circ} \mathrm{C}$ in order to maintain folding [85]. After $6.5 \mathrm{~h}$, the gel was dried, exposed to a phosphorscreen, and imaged using a Bio-Rad Personal Molecular Imager.

\section{Chemical and Enzymatic Mapping}

RNAs used in all mapping experiments were folded as described for native gel analysis. Each sample had a final buffer and monovalent ion composition of $10 \mathrm{mM}$ Tris $(\mathrm{pH} 7)$ and $100 \mathrm{mM}$ KCl. HPMut contained $10 \mathrm{mM} \mathrm{Mg}^{2+}$ or $5 \mathrm{mM}\left[\mathrm{Co}\left(\mathrm{NH}_{3}\right)_{6}\right]^{3+}, \mathrm{PK}$ $5 \mathrm{mM}\left[\mathrm{Co}\left(\mathrm{NH}_{3}\right)_{6}\right]^{3+}$ and HP no multivalent ions. Enzymatic and small molecule mapping was carried out at room temperature.

RNase $I_{f}, A, T 1$, and $V 1$ reactions, alkaline hydrolysis and RNase T1 ladder were adapted from manufacturer's protocol (Ambion, Inc and New England Biolabs) and carried out on 5' end labeled RNAs (50,000 cpm per reaction). Optimal enzymatic concentrations were determined with enzyme titrations. The digestion reactions were stopped by ethanol precipitation at $-20^{\circ} \mathrm{C}$. The resulting pellet was dissolved in gel loading buffer and fractionated on a denaturing, $8 \%$ polyacrylamide gel.
$\mathrm{Pb}^{2+}$ cleavage reactions were carried out by incubating $5^{\prime}$ end labeled RNAs with $1 \mathrm{mM} \quad \mathrm{Pb}(\mathrm{OAc})_{2} \quad$ [86,87]. Aliquots $(50,000 \mathrm{cpm}$ per aliquot) were removed at $0,0.5,1,2,4,8,15$, 30 , and $60 \mathrm{~min}$. The reaction was stopped by placing the aliquots in gel loading buffer and freezing at $-80^{\circ} \mathrm{C}$ until they were fractionated on a denaturing, 8\% polyacrylamide gel. DEPC reactions were carried out by incubating $5^{\prime}$ end labeled RNAs (50,000 cpm per reaction) with $0.69 \mathrm{mM}$ DEPC, followed by $\mathrm{NaBH} 4$ reduction and aniline cleavage. Reactions were stopped by precipitation at $-20^{\circ} \mathrm{C}$ and the resulting pellet was dissolved in gel loading buffer and fractionated on a denaturing, 8\% polyacrylamide gel.

Unlabeled 3PSS RNA (0.5 $\mu \mathrm{g}$ per reaction) was modified with optimized concentrations of DMS, CMCT, and NMIA using published protocols $[87,88]$. Modifications were read out by primer extension (primer sequence: 5'-ACATCTGCACTCCG$3^{\prime}$, chemically synthesized by IDT, and $5^{\prime}$ end labeled with $\gamma-{ }^{32} \mathrm{P}$ ATP) with $100,000 \mathrm{cpm}$ per reaction, followed by separation of fragments by denaturing $8 \%$ PAGE.

All gels were dried, exposed to phosphorscreen, and imaged with a Bio-Rad Personal Molecular Imager. Gel images were analyzed with ImageJ [89]. Bands were quantified by taking the integrated pixel density and normalizing with respect to the highest intensity band after subtraction of background observed in negative controls, which were treated as for reactions, but with omission of the modifying reagent. For $\mathrm{Pb}^{2+}$ cleavage, equal amounts of radioactivity were loaded in each lane and so all bands were normalized to A704 of PK, which was the most intense in any gel.

\section{Hybridization to Oligonucleotide Microarrays}

About 200,000 cpm of labeled RNA was folded as described above before hybridization to oligonucleotide microarrays $[32,38,90,91]$. Each of the 861 probes was spotted in triplicate. Spotting buffer, monomer U, and pentamer UUUUU, which should show no binding to 3PSS, were also printed on the microarray as internal negative controls. Hybridizations were carried out in folding buffer for $18 \mathrm{~h}$ at $4^{\circ} \mathrm{C}$. Microarrays were washed for $1 \mathrm{~min}$ at $0^{\circ} \mathrm{C}$ and then dried by centrifugation. Hybridization was visualized by exposure to a phosphorimager screen and quantitative analysis was performed with ArrayGaugeV2.1. Binding was considered strong, medium and weak, when the integrated intensities were $\geq 1 / 3, \geq 1 / 9$ and $\geq 1 / 27$ of the strongest integrated intensity, respectively. Alternative binding sites were predicted using RNA-RNA thermodynamics [92,93].

\section{Sequence Alignment and Analysis}

All full-length, non-redundant influenza A sequences $(13,277)$ were downloaded from the National Center for Biotechnology Information (NCBI) influenza virus resource page [94]. An alignment was generated with the MAFFT alignment algorithm's FFT-NS-1 method [95]. The 3PSS region was cut from the large alignment and sequence duplicates were collapsed using a PERL script to identify 734 unique sequences. The nucleotide alignment was converted to amino acids in silico, re-aligned with ClustalW [96], manually refined, then converted back into nucleotides. Base pairing frequencies from each model (Fig. 3A,B) were analyzed with respect to the whole alignment and each unique sequence using PERL scripts.

Free energies at $37^{\circ} \mathrm{C}$ were predicted for the hairpin and pseudoknot conformations with a nearest neighbor thermodynamic model $[92,93,97,98]$ and pseudoknot loop entropy model [99]. 


\section{Supporting Information}

Figure S1 Results of experimental mapping. Specific reagent is indicated by colored shapes (see figure key). Reactivity $\geq 2 / 3$ the strongest band is indicated with solid shapes, while reactivity $<2 / 3$ but $\geq 1 / 3$ the strongest band is indicated by open shapes. All folding buffers contained $10 \mathrm{mM}$ Tris (pH7), $100 \mathrm{mM}$ $\mathrm{KCl}$. Mapping results for: $(\mathbf{A})$ 3PSS folded in $5 \mathrm{mM}\left[\mathrm{Co}\left(\mathrm{NH}_{3}\right)_{6}\right]^{3+}$ (PK). (B) 3PSS folded without $\mathrm{Mg}^{2+}$ or $\left[\mathrm{Co}\left(\mathrm{NH}_{3}\right)_{6}\right]^{3+}(\mathrm{HP})$ RNase A reactivity is not annotated because RNA is over-digested at the same enzyme concentration that yielded good results in PK and HPMut. (G) HPMut folded in $5 \mathrm{mM}\left[\mathrm{Co}\left(\mathrm{NH}_{3}\right)_{6}\right]^{3+}$, and mapped with $\mathrm{Pb}^{2+}$ and RNases $\mathrm{A}$ and $\mathrm{T} 1$. (D) HPMut folded in $10 \mathrm{mM}$ $\mathrm{Mg}^{2+}$. (E) 3PSS folded in $10 \mathrm{mM} \mathrm{Mg}{ }^{2+}$ which gives roughly equal amounts of PK and HP. Results are annotated on both structure models (SHAPE mapping was not performed on the mixture). RNase V1 was only used when folding conditions contained $\mathrm{Mg}^{2+}$, which is essential to enzyme activity [82]. Dark and light orange letters represent strong and moderate RNase V1 hits.

(TIF)

Figure S2 Gel results for primer extension. Readouts of DMS, kethoxal, and CMCT experiments on pseudoknot (PK), hairpin (HP), and hairpin mutant (HPMut) are shown. The first four lanes are dideoxy ladders and the remaining are for experiments on each RNA target. Unmodified RNA experimental controls (Exp. Control) were run alongside each set of experiments to show natural stops induced by target structure. Interpretable primer extension data for PK stretches from nts 683 to 715 . (TIF)

Figure S3 Gel results for enzymatic mapping experiments on HP and PK. T1 ladders and hydrolysis ladders $(\mathrm{OH}$ ladders) are run alongside mapping lanes to identify cleavage sites. For each enzyme the black wedge indicates the increasing range of enzyme used: RNase $\mathrm{I}_{\mathrm{f}}$ had $50 \mathrm{U}, 5 \mathrm{U}, 0.5 \mathrm{U}$; RNase A had $1 \mathrm{ng}$, $0.1 \mathrm{ng}$ and $0.01 \mathrm{ng}$; and RNAse $\mathrm{T} 1$ had $1 \mathrm{U}, 0.1 \mathrm{U}$, and $0.01 \mathrm{U}$. The last lane is an experimental control for RNA treated the same as enzyme reactions, but without any enzyme.

(TIF)

\section{References}

1. Hilleman MR (2002) Realities and enigmas of human viral influenza: pathogenesis, epidemiology and control. Vaccine 20: 3068-3087.

2. Johnson NP, Mueller J (2002) Updating the accounts: global mortality of the 1918-1920 "Spanish" influenza pandemic. Bull Hist Med 76: 105-115.

3. World Health Organization (WHO) (2009) Influenza (Seasonal) Fact sheet $\mathrm{N}^{\circ}$ 211.

4. Dushoff J, Plotkin JB, Viboud C, Earn DJ, Simonsen L (2006) Mortality due to influenza in the United States-an annualized regression approach using multiple-cause mortality data. Am J Epidemiol 163: 181-187.

5. Thompson WW, Shay DK, Weintraub E, Brammer L, Cox N, et al. (2003) Mortality associated with influenza and respiratory syncytial virus in the United States. JAMA 289: 179-186.

6. Thompson WW, Shay DK, Weintraub E, Brammer L, Bridges CB, et al. (2004) Influenza-associated hospitalizations in the United States. JAMA 292: 1333-1340.

7. Du QS, Huang RB, Wang SQ, Chou KC (2010) Designing inhibitors of M2 proton channel against H1N1 swine influenza virus. PLoS One 5: e9388.

8. Ge Q, Filip L, Bai A, Nguyen T, Eisen HN, et al. (2004) Inhibition of influenza virus production in virus-infected mice by RNA interference. Proc Natl Acad Sci U S A 101: 8676-8681.

9. Tompkins SM, Lo CY, Tumpey TM, Epstein SL (2004) Protection against lethal influenza virus challenge by RNA interference in vivo. Proc Natl Acad Sci U S A 101: 8682-8686.

10. Moss WN, Priore SF, Turner DH (2011) Identification of potential conserved RNA secondary structure throughout influenza A coding regions. RNA 17: 991-1011.

11. Shih SR, Krug RM (1996) Novel exploitation of a nuclear function by influenza virus: the cellular SF2/ASF splicing factor controls the amount of the essential viral M2 ion channel protein in infected cells. EMBO J 15: 5415-5427.
Table S1 Table of results for microarray hybridization experiments. (XLSX)

Table S2 Base pairing frequencies and percent canonical pairing. Pseudoknot $(\mathrm{PK})$ and hairpin $(\mathrm{HP})$ conformation counts based on an alignment of unique sequences and also all available sequences. Data for PK and the helixes P1 and P2 in HP are shown in the top box. The $\mathrm{P} 3$ helix of HP is shown in the bottom box. Paired sites are indicated by the $i$ and $j$ locations of the $5^{\prime}$ and $3^{\prime}$ nts. Symmetric loop sites are given in italics. Helixes are colored purple for $\mathrm{P} 0$, orange for $\mathrm{P} 1$, green for $\mathrm{P} 2$, and blue for P3/P3'. Mutations expected to be compensatory (double point mutations that preserve pairing) are annotated in blue. Mutations expected to be consistent (single point mutations that maintain pairing) are annotated in green. The last column gives the percentage of the time $\mathrm{i}$ and $\mathrm{j}$ are canonically paired in the alignment of all unique sequences. Also included are the base pair type percentages by helix and averaged across helices.

(XLSX)

Table S3 Table with GenBank accession numbers and sequences used in this study. Unique sequences are ranked according to their ability to form stable secondary structure. The most stable are at the top, while the least stable are at the bottom. Relative stability is estimated as the fraction of GC pairs multiplied by the fraction of nucleotides in canonical pairs (color annotated red to green for both $\mathrm{PK}$ and $\mathrm{HP}$ ). Also shown are the number of sequences that collapse into each unique sequence, the host specificity and the viral strain.

(XLSX)

Table S4 Counts for putative base triples. The most frequent triple is in red and the second most frequent in orange. (XLSX)

\section{Author Contributions}

Conceived and designed the experiments: WN LIDM DHT. Performed the experiments: WN LIDM EK. Analyzed the data: WN LIDM EK DHT. Contributed reagents/materials/analysis tools: SFP EK RK. Wrote the paper: WM LIDM EK DHT.

12. Lamb RA, Lai CJ, Choppin PW (1981) Sequences of mRNAs derived from genome RNA segment 7 of influenza virus: colinear and interrupted mRNAs code for overlapping proteins. Proc Natl Acad Sci U S A 78: 4170-4174.

13. Jenkins JL, Shen H, Green MR, Kielkopf CL (2008) Solution conformation and thermodynamic characteristics of RNA binding by the splicing factor U2AF65. J Biol Chem 283: 33641-33649.

14. Robb NC, Fodor E (2011) The accumulation of influenza A virus segment 7 spliced mRNAs is regulated by the NS1 protein. J Gen Virol 93: 113-118.

15. Shih SR, Nemeroff ME, Krug RM (1995) The choice of alternative 5' splice sites in influenza virus M1 mRNA is regulated by the viral polymerase complex. Proc Natl Acad Sci U S A 92: 6324-6328.

16. Gultyaev AP, Heus HA, Olsthoorn RC (2007) An RNA conformational shift in recent $\mathrm{H} 5 \mathrm{~N} 1$ influenza A viruses. Bioinformatics 23: 272-276.

17. Gultyaev AP, Olsthoorn RC (2010) A family of non-classical pseudoknots in influenza A and B viruses. RNA Biol 7: 125-129.

18. Jacquenet S, Ropers D, Bilodeau PS, Damier L, Mougin A, et al. (2001) Conserved stem-loop structures in the HIV-1 RNA region containing the A3 3' splice site and its cis-regulatory element: possible involvement in RNA splicing. Nucleic Acids Res 29: 464-478.

19. Singh NN, Singh RN, Androphy EJ (2007) Modulating role of RNA structure in alternative splicing of a critical exon in the spinal muscular atrophy genes. Nucleic Acids Res 35: 371-389.

20. Loeb DD, Mack AA, Tian R (2002) A secondary structure that contains the $5^{\prime}$ and $3^{\prime}$ splice sites suppresses splicing of duck hepatitis B virus pregenomic RNA. J Virol 76: 10195-10202.

21. Watakabe A, Inoue K, Sakamoto H, Shimura Y (1989) A secondary structure at the $3^{\prime}$ splice site affects the in vitro splicing reaction of mouse immunoglobulin mu chain pre-mRNAs. Nucleic Acids Res 17: 8159-8169. 
22. Muro AF, Caputi M, Pariyarath R, Pagani F, Buratti E, et al. (1999) Regulation of fibronectin EDA exon alternative splicing: possible role of RNA secondary structure for enhancer display. Mol Cell Biol 19: 2657-2671.

23. Domenjoud L, Gallinaro H, Kister L, Meyer S, Jacob M (1991) Identification of a specific exon sequence that is a major determinant in the selection between a natural and a cryptic 5' splice site. Mol Cell Biol 11: 4581-4590.

24. Buratti E, Muro AF, Giombi M, Gherbassi D, Iaconcig A, et al. (2004) RNA folding affects the recruitment of SR proteins by mouse and human polypurinic enhancer elements in the fibronectin EDA exon. Mol Cell Biol 24: 1387-1400.

25. Mei HY, Cui M, Heldsinger A, Lemrow SM, Loo JA, et al. (1998) Inhibitors of protein-RNA complexation that target the RNA: specific recognition of human immunodeficiency virus type 1 TAR RNA by small organic molecules. Biochemistry 37: 14204-14212.

26. Sucheck SJ, Wong CH (2000) RNA as a target for small molecules. Curr Opin Chem Biol 4: 678-686.

27. Wilson WD, Li K (2000) Targeting RNA with small molecules. Curr Med Chem 7: 73-98.

28. Disney MD, Labuda LP, Paul DJ, Poplawski SG, Pushechnikov A, et al. (2008) Two-dimensional combinatorial screening identifies specific aminoglycosideRNA internal loop partners. J Am Chem Soc 130: 11185-11194.

29. Labuda LP, Pushechnikov A, Disney MD (2009) Small molecule microarrays of RNA-focused peptoids help identify inhibitors of a pathogenic group I intron. ACS Chem Biol 4: 299-307.

30. Childs JL, Disney MD, Turner DH (2002) Oligonucleotide directed misfolding of RNA inhibits Candida albicans group I intron splicing. Proc Natl Acad Sci U S A 99: 11091-11096.

31. Disney MD, Childs JL, Turner DH (2004) New approaches to targeting RNA with oligonucleotides: inhibition of group I intron self-splicing. Biopolymers 73 : $151-161$.

32. Kierzek E (2009) Binding of short oligonucleotides to RNA: studies of the binding of common RNA structural motifs to isoenergetic microarrays. Biochemistry 48: 11344-11356.

33. Ehresmann C, Baudin F, Mougel M, Romby P, Ebel JP, et al. (1987) Probing the structure of RNAs in solution. Nucleic Acids Res 15: 9109-9128.

34. Ciesiolka J, Michalowski D, Wrzesinski J, Krajewski J, Krzyzosiak WJ (1998) Patterns of cleavages induced by lead ions in defined RNA secondary structure motifs. J Mol Biol 275: 211-220.

35. Kirsebom L, Ciesiolka J (2005) $\mathrm{Pb}^{2+}$-induced cleavage of RNA. In: Hartmann R, Bindereif A, Schon A, Westhof E, eds. Handbook of RNA Biochemistry. Weinheim: WILEY-VCH. pp 214-228.

36. Merino EJ, Wilkinson KA, Coughlan JL, Weeks KM (2005) RNA structure analysis at single nucleotide resolution by selective 2 '-hydroxyl acylation and primer extension (SHAPE). J Am Chem Soc 127: 4223-4231.

37. Pasternak A, Kierzek E, Pasternak K, Turner DH, Kierzek R (2007) A chemical synthesis of LNA-2,6-diaminopurine riboside, and the influence of 2'-O-methyl2,6-diaminopurine and LNA-2,6-diaminopurine ribosides on the thermodynamic properties of 2'-O-methyl RNA/RNA heteroduplexes. Nucleic Acids Res 35: 4055-4063.

38. Kierzek E, Christensen SM, Eickbush TH, Kierzek R, Turner DH, et al. (2009) Secondary structures for $5^{\prime}$ regions of R2 retrotransposon RNAs reveal a novel conserved pseudoknot and regions that evolve under different constraints. J Mol Biol 390: 428-442.

39. Pasternak A, Kierzek E, Pasternak K, Fratczak A, Turner DH, et al. (2008) The thermodynamics of $3^{\prime}$-terminal pyrene and guanosine for the design of isoenergetic 2'-O-methyl-RNA-LNA chimeric oligonucleotide probes of RNA structure. Biochemistry 47: 1249-1258.

40. Kierzek E, Ciesielska A, Pasternak K, Mathews DH, Turner DH, et al. (2005) The influence of locked nucleic acid residues on the thermodynamic properties of 2'-O-methyl RNA/RNA heteroduplexes. Nucleic Acids Res 33: 5082-5093.

41. Palese P (2004) Influenza: old and new threats. Nat Med 10: S82-87.

42. Madjid M, Lillibridge S, Mirhaji P, Casscells W (2003) Influenza as a bioweapon. J R Soc Med 96: 345-346.

43. Krug RM (2003) The potential use of influenza virus as an agent for bioterrorism. Antiviral Res 57: 147-150.

44. Fouchier RA, Garcia-Sastre A, Kawaoka Y (2012) Pause on avian flu transmission studies. Nature 481: 443.

45. Stiver G (2003) The treatment of influenza with antiviral drugs. CMAJ 168: 49-56.

46. Deshler JO, Rossi JJ (1991) Unexpected point mutations activate cryptic 3' splice sites by perturbing a natural secondary structure within a yeast intron. Genes Dev 5: 1252-1263.

47. Jaeger L, Westhof E, Michel F (1996) Function of a pseudoknot in the suppression of an alternative splicing event in a group I intron. Biochimie 78: 466-473.

48. Warf MB, Berglund JA (2010) Role of RNA structure in regulating pre-mRNA splicing. Trends Biochem Sci 35: 169-178.

49. Warf MB, Diegel JV, von Hippel PH, Berglund JA (2009) The protein factors MBNL1 and U2AF65 bind alternative RNA structures to regulate splicing. Proc Natl Acad Sci U S A 106: 9203-9208.

50. Honig A, Auboeuf D, Parker MM, O’Malley BW, Berget SM (2002) Regulation of alternative splicing by the ATP-dependent DEAD-box RNA helicase p72. Mol Cell Biol 22: 5698-5707.
51. Cheah MT, Wachter A, Sudarsan N, Breaker RR (2007) Control of alternative RNA splicing and gene expression by eukaryotic riboswitches. Nature 447: 497-500.

52. Winkler W, Nahvi A, Breaker RR (2002) Thiamine derivatives bind messenger RNAs directly to regulate bacterial gene expression. Nature 419: 952-956.

53. Nixon PL, Theimer CA, Giedroc DP (1999) Thermodynamics of stabilization of RNA pseudoknots by cobalt(III) hexaammine. Biopolymers 50: 443-458.

54. Gonzalez RL Jr., Tinoco I Jr. (1999) Solution structure and thermodynamics of a divalent metal ion binding site in an RNA pseudoknot. J Mol Biol 289: $1267-1282$.

55. Heilman-Miller SL, Thirumalai D, Woodson SA (2001) Role of counterion condensation in folding of the Tetrahymena ribozyme. I. Equilibrium stabilization by cations. J Mol Biol 306: 1157-1166.

56. Heilman-Miller SL, Pan J, Thirumalai D, Woodson SA (2001) Role of counterion condensation in folding of the Tetrahymena ribozyme. II. Counterion-dependence of folding kinetics. J Mol Biol 309: 57-68.

57. Rudisser S, Tinoco I Jr. (2000) Solution structure of Cobalt(III)hexammine complexed to the GAAA tetraloop, and metal-ion binding to G.A mismatches. J Mol Biol 295: 1211-1223.

58. Chen C, Zhao X, Kierzek R, Yu YT (2010) A flexible RNA backbone within the polypyrimidine tract is required for $\mathrm{U} 2 \mathrm{AF} 65$ binding and pre-mRNA splicing in vivo. Mol Cell Biol 30: 4108-4119.

59. Brown RS, Dewan JC, Klug A (1985) Crystallographic and biochemical investigation of the lead(II)-catalyzed hydrolysis of yeast phenylalanine tRNA. Biochemistry 24: 4785-4801.

60. Streicher B, von Ahsen U, Schroeder R (1993) Lead cleavage sites in the core structure of group I intron-RNA. Nucleic Acids Res 21: 311-317.

61. Barik S (2010) siRNA for Influenza Therapy. Viruses 2: 1448-1457.

62. Tan X, Lu ZJ, Gao G, Xu Q, Hu L, et al. (2012) Tiling genomes of pathogenic viruses identifies potent antiviral shRNAs and reveals a role for secondary structure in shRNA efficacy. Proc Natl Acad Sci U S A 109: 869-874.

63. Aggarwal S, Bradel-Tretheway B, Takimoto T, Dewhurst S, Kim B (2010) Biochemical characterization of enzyme fidelity of influenza A virus RNA polymerase complex. PLoS One 5: e10372.

64. Jang SB, Hung LW, Chi YI, Holbrook EL, Carter RJ, et al. (1998) Structure of an RNA internal loop consisting of tandem C-A+ base pairs. Biochemistry 37: $11726-11731$.

65. Gutell RR, Larsen N, Woese CR (1994) Lessons from an evolving rRNA: 16S and 23S rRNA structures from a comparative perspective. Microbiol Rev 58: $10-26$.

66. Pace NR, Smith DK, Olsen GJ, James BD (1989) Phylogenetic comparative analysis and the secondary structure of ribonuclease P RNA-a review. Gene 82: $65-75$.

67. Frank DN, Adamidi C, Ehringer MA, Pitulle C, Pace NR (2000) Phylogeneticcomparative analysis of the eukaryal ribonuclease P RNA. RNA 6: 1895-1904.

68. Frugier M, Schimmel P (1997) Subtle atomic group discrimination in the RNA minor groove. Proc Natl Acad Sci U S A 94: 11291-11294.

69. Hermann T, Westhof E (1999) Non-Watson-Crick base pairs in RNA-protein recognition. Chem Biol 6: R335-343.

70. Disney MD, Haidaris CG, Turner DH (2001) Recognition elements for 5' exon substrate binding to the Candida albicans group I intron. Biochemistry 40: 6507-6519.

71. Lerman YV, Kennedy SD, Shankar N, Parisien M, Major F, et al. (2011) NMR structure of a 4 x 4 nucleotide RNA internal loop from an R2 retrotransposon: Identification of a three purine-purine sheared pair motif and comparison to MC-SYM predictions. RNA 17: 1664-1677.

72. Nagaswamy U, Voss N, Zhang Z, Fox GE (2000) Database of non-canonical base pairs found in known RNA structures. Nucleic Acids Res 28: 375-376.

73. Ban N, Nissen P, Hansen J, Moore PB, Steitz TA (2000) The complete atomic structure of the large ribosomal subunit at $2.4 \mathrm{~A}$ resolution. Science 289: 905-920.

74. Dallas A, Moore PB (1997) The loop E-loop D region of Escherichia coli 5S rRNA: the solution structure reveals an unusual loop that may be important for binding ribosomal proteins. Structure 5: 1639-1653.

75. Hung LW, Holbrook EL, Holbrook SR (2000) The crystal structure of the Rev binding element of HIV-1 reveals novel base pairing and conformational variability. Proc Natl Acad Sci U S A 97: 5107-5112.

76. Abu Almakarem AS, Petrov AI, Stombaugh J, Zirbel CL, Leontis NB (2011) Comprehensive survey and geometric classification of base triples in RNA structures. Nucleic Acids Res 40: 1407-1423.

77. Theimer CA, Blois CA, Feigon J (2005) Structure of the human telomerase RNA pseudoknot reveals conserved tertiary interactions essential for function. $\mathrm{Mol}$ Cell 17: 671-682.

78. Cornish PV, Giedroc DP (2006) Pairwise coupling analysis of helical junction hydrogen bonding interactions in luteoviral RNA pseudoknots. Biochemistry 45 : $11162-11171$.

79. Ulyanov NB, Shefer K, James TL, Tzfati Y (2007) Pseudoknot structures with conserved base triples in telomerase RNAs of ciliates. Nucleic Acids Res 35: $6150-6160$.

80. Cao S, Giedroc DP, Chen SJ (2010) Predicting loop-helix tertiary structural contacts in RNA pseudoknots. RNA 16: 538-552.

81. Theimer CA, Wang Y, Hoffman DW, Krisch HM, Giedroc DP (1998) Nonnearest neighbor effects on the thermodynamics of unfolding of a model mRNA pseudoknot. J Mol Biol 279: 545-564. 
82. Holland JA, Hansen MR, Du Z, Hoffman DW (1999) An examination of coaxial stacking of helical stems in a pseudoknot motif: the gene 32 messenger RNA pseudoknot of bacteriophage T2. RNA 5: 257-271.

83. Massin P, Kuntz-Simon G, Barbezange C, Deblanc C, Oger A, et al. (2009) Temperature sensitivity on growth and/or replication of H1N1, H1N2 and H3N2 influenza A viruses isolated from pigs and birds in mammalian cells. Vet Microbiol 142: 232-241.

84. Priore SF, Moss WN, Turner DH (2012) Influenza A Virus Coding Regions Posses Host-specific Global Ordered RNA Structure. PLoS One 7: e35989.

85. Woodson SA (2001) Probing RNA folding pathways by RNA fingerprinting. Curr Protoc Nucleic Acid Chem Chapter 11: Unit 1114.

86. Kierebom L, Ciesiolka J (2005) Pb2+-induced Cleavage of RNA. In: Hartmann RK BA, Schon A, Westhof E, eds. Handbook of RNA Biochemistry. Weinheim: Wiley-VCH. pp 214-228.

87. Ziehler WA, Engelke DR (2001) Probing RNA structure with chemical reagents and enzymes. Curr Protoc Nucleic Acid Chem Chapter 6: Unit 61.

88. Wilkinson KA, Merino EJ, Weeks KM (2006) Selective 2'-hydroxyl acylation analyzed by primer extension (SHAPE): quantitative RNA structure analysis at single nucleotide resolution. Nat Protoc 1: 1610-1616.

89. Girish V, Vijayalakshmi A (2004) Affordable image analysis using NIH Image/ ImageJ. Indian J Cancer 41: 47.

90. Kierzek E, Kierzek R, Moss WN, Christensen SM, Eickbush TH, et al. (2008) Isoenergetic penta- and hexanucleotide microarray probing and chemical mapping provide a secondary structure model for an RNA element orchestrating R2 retrotransposon protein function. Nucleic Acids Res 36: 1770-1782.

91. Liang R, Kierzek E, Kierzek R, Turner DH (2010) Comparisons between chemical mapping and binding to isoenergetic oligonucleotide microarrays reveal unexpected patterns of binding to the Bacillus subtilis RNase P RNA specificity domain. Biochemistry 49: 8155-8168.

92. Xia T, SantaLucia J Jr., Burkard ME, Kierzek R, Schroeder SJ, et al. (1998) Thermodynamic parameters for an expanded nearest-neighbor model for formation of RNA duplexes with Watson-Crick base pairs. Biochemistry 37: 14719-14735.

93. Turner DH, Mathews DH (2009) NNDB: the nearest neighbor parameter database for predicting stability of nucleic acid secondary structure. Nucleic Acids Res 38: D280-282.

94. Bao Y, Bolotov P, Dernovoy D, Kiryutin B, Zaslavsky L, et al. (2008) The influenza virus resource at the National Center for Biotechnology Information. J Virol 82: 596-601.

95. Katoh K, Kuma K, Toh H, Miyata T (2005) MAFFT version 5: improvement in accuracy of multiple sequence alignment. Nucleic Acids Res 33: 511-518.

96. Larkin MA, Blackshields G, Brown NP, Chenna R, McGettigan PA, et al. (2007) Clustal W and Clustal X version 2.0. Bioinformatics 23: 2947-2948.

97. Mathews DH, Disney MD, Childs JL, Schroeder SJ, Zuker M, et al. (2004) Incorporating chemical modification constraints into a dynamic programming algorithm for prediction of RNA secondary structure. Proc Natl Acad Sci U S A 101: 7287-7292.

98. Chen JL, Dishler AL, Kennedy SD, Yildirim I, Liu B, et al. (2012) Testing the Nearest Neighbor Model for Canonical RNA Base Pairs: Revision of GU Parameters. Biochemistry 51: 3508-3522.

99. Cao S, Chen SJ (2006) Predicting RNA pseudoknot folding thermodynamics. Nucleic Acids Res 34: 2634-2652. 